\title{
PENGARUH PERCEIVED SERVICE QUALITY TERHADAP CUSTOMER LOYALTY DENGAN CUSTOMER SATISFACTION SEBAGAI VARIABLE INTERVENING DI HOTEL KARTIKA GRAHA MALANG
}

\author{
Eva Yohana Sudjianto ${ }^{1}$, Edwin Japarianto ${ }^{1 *}$ \\ ${ }^{1}$ Program Manajemen Pemasaran, Fakultas Ekonomi, Universitas Kristen Petra \\ Jl. Siwalankerto 121-131, Surabaya \\ E-mail: evayohanas@yahoo.com; edwinj@petra.ac.id \\ *Korespondensi penulis
}

\begin{abstract}
Abstrak: Penelitian ini bertujuan untuk mengetahui pengaruh dari Perceived Service Quality, Customer Satisfaction dan Customer Loyalty dengan studi kasus Hotel Kartika Graha Malang. Penelitian ini mengunakan teknik penelitian kuantitatif kausal. Sample yang digunakan dalam penelitian ini adalah konsumen atau tamu yang merupakan rombongan (keluarga, teman ), menginap minimal 1 malam dan juga menginap dalam durasi antara bulan November 2016 - April 2017 sebanyak 100 kuisioner. Penelitian ini menggunakan teknik analisa SEM (Structural Equation Modeling). Penelitian ini menunjukan bahwa semua variabel adalah berpengaruh positif dan juga customer satisfaction terbukti menjadi variabel intervening antara perceived service quality dan customer loyalty.
\end{abstract}

Kata kunci: Perceived service quality, customer satisfaction, customer loyalty.

\begin{abstract}
The purpose of this research is to determine the effect of the Perceived Service Quality, Customer Satisfaction and Customer Loyalty with a case study Kartika Graha Hotel Malang. This type of research is conclusive causal. The samples of this research are consumers or guest (family,friends) who have stayed minimum one night and in the period from November 2016 until April 2017, which amounts 100 questionnaires. This study uses analysis techniques Structural Equation Modeling (SEM). The result of this study indicates that all of variable are affect positively and customer satisfaction as intervening variable has positively impact to Perceived Service Quality and Customer Loyalty.
\end{abstract}

Keywords: Perceived service quality, customer satisfaction, customer loyalty.

\section{PENDAHULUAN}

Sektor pariwisata di Indonesia meningkat setiap tahunnya, banyak destinasi pariwisata yang menarik dibeberapa daerah salah satunya adalah kota Malang. Kota Malang berada di provinsi Jawa Timur, yang merupakan kota terbesar kedua setelah kota Surabaya. Kota Malang sendiri lebih sebagai penyedia jasa, seperti hotel, restoran, serta pusat-pusat hiburan dan perbelanjaan dan wilayah sekitarnya seperti kabupaten malang dan kota batu adalah sebagai tempat wisata.

Perhotelan di kota Malang adalah salah satu dari beberapa sektor pendukung pariwisata yang meningkatnya pesat. Perhotelan disini sangat penting gunanya untuk wisatawan yang ingin berpariwisata dalam jangka waktu yang lama sehingga menggunakan hotel sebagai tempat mereka tinggal untuk sementara. Oleh karena itu pertumbuhan hotel di Kota Malang meningkat naik setiap tahunnya, dari fenomena tersebut perusahaan jasa perhotelan terus berlombalomba untuk menggaet konsumen dengan cara memberikan service quality yang terbaik ketika konsumen menginap dihotel mereka, dan diharapkan konsumen tersebut menjadi konsumen yang loyal.
Perceived service quality merupakan ukuran selisih antara harapan konsumen dengan pelayanan yang diberikan oleh perusahaan. Stefano et al, (2015) juga berpendapat sama bahwa service quality dipengaruhi oleh pelayanan yang dirasakan dan layanan yang diharapkan. Menurut Vazquez et al (2000), dikatakan bahwa dalam sebuah layanan, ketika ekspektasi melebihi dari harapan akan disebut bahwa pelayanan tersebut adalah memuaskan, dan dianggap buruk/ tidak memuaskan ketika ekspektasi tidak sama dengan harapan atau dibawah standart harapan konsumen. Jadi dalam perusahaan jasa perhotelan, memuaskan konsumen dengan melakukan service terbaik adalah yang penting untuk membentuk penilaian/persepsi dari konsumen terhadap sebuah layanan jasa. Kepuasan yang konsumen rasakan jika semakin tinggi, maka akan semakin tinggi pula tingkat konsumen untuk kembali membeli atau menginap di hotel tersebut (Jasinskas et al, 2016).

Hotel Kartika Graha Malang merupakan hotel bintang 3 dengan standar internasional, berdiri pada 26 agustus 1989 dan berada di Jalan Jaksa Agung Suprapto no 17 Malang tepat di jalan utama di tengah kota Malang. Total jumlah lantai yang dimiliki hotel ini ada 8 lantai dan memiliki total 79 kamar yang 
terdiri dari beberapa kelas. Hotel ini termasuk ke dalam klasifikasi hotel sedang namun tetap terkesan mewah. Disini penulis ingin mengetahui apakah perceived service quality yang diberikan oleh Hotel Kartika Graha Malang sudah disukai, cocok dan dapat memuaskan konsumen, dimensi apa yang paling mempengaruhi customer sastisfaction, dan selanjutnya dari konsumen yang puas dapat membuat konsumen menjadi loyal. Maka dari itu penulis ingin melakukan penelitian "Pengaruh Perceived Service Quality terhadap Customer Loyalty dengan Customer Satisfaction sebagai Variabel Intervening di Hotel Kartika Graha Malang".

\section{LANDASAN TEORI}

\section{Perceived Service Quality}

Menurut Zeithaml et al, (1990:19) "service quality as perceived by customers can be defined as the extent of discrepancy between customer expectation or desires and their perceptions". Kualitas layanan seperti yang dirasakan oleh konsumen dapat didefinisikan sebagai sejauh mana perbedaan antara harapan konsumen atau keinginan dan persepsi mereka. Penerapan service quality telah menjadi strategi dari beberapa industri, termasuk perusahaan jasa hotel. Dalam perusahaan jasa hotel, kualitas pelayanan merupakan salah satu startegi dalam pencapaian kepuasan tamu hotel. Keberhasilan perusahaan dalam memberikan pelayanan yang bermutu kepada para pelanggannya, pencapaian pangsa pasar yang tinggi, serta peningkatan profit perusahaan tersebut sangat ditentukan oleh pendekatan yang digunakan (Parasuraman et al, 1985).

Dalam perkembangannya dimensi perceived service quality mengalami beberapa perubahan dan perkembangan. Setelah banyak penelitian yang berkembang, (Parasuraman et al, 1988) mengusulkan skala kualitas pelayanan yang disebut SERVQUAL, perceived service quality disini memiliki 5 dimensi yaitu:

1. Tangibles (berwujud) yaitu segala sesuatu yang menggambarkan wujud secara fisik yang mendukung operasional jasa. Contohnya adalah fasilitas fisik (gedung, interior bangunan), perlengkapan yang modern (Kamar tidur, kamar mandi), penampilan karyawan, kebersihan dan kenyamanan hotel.

2. Reliability (keandalan) yaitu kemampuan perusahaan untuk melayani sesuai dengan apa yang dijanjikan secara akurat. Contohnya adalah seperti keakuratan harga yang diberikan, ketepatan, pelayanan yang konsisten sesuai dengan standart yang ada setiap saat.
3. Responsiveness (cepat/tanggap) yaitu kemampuan perusahaan untuk melayani konsumen dengan cepat dan tanggap. Contohnya adalah karyawan dapat memberikan pelayanan yang cepat, permintaan dan keluhan pelanggan secara tepat tanggap, karyawan selalu bersedia untuk memberikan layanan.

4. Assurance (jaminan) yaitu perusahaan atau karyawan dapat membangun kepercayaan dan keyakinan terhadap konsumennya, konsumen merasa aman untuk bertransaksi dengan perusahaan, harus memiliki kemampuan untuk menjawab dengan baik, sikap dan sifat karyawan yang sopan dalam menghadapi konsumen .

5. Emphaty (empati) yaitu sikap perhatian dan peduli penuh yang diberikan pada konsumen. Contohnya adalah karyawan dapat mengerti dan memenuhi kebutuhan konsumen secara spesifik, perusahaan memberikan perhatian penuh kepada tiap individu konsumennya.

\section{Customer Satisfaction}

Kepuasan pelanggan akan timbul jika kebutuhan dan keinginan konsumen dapat terpenuhi oleh barang atau jasa yang berkualitas. Puas atau tidaknya konsumen terhadap suatu barang atau jasa ditentukan oleh perilaku yang tampak setelah menggungkan barang atau jasa tersebut. Customer satisfaction merupakan penilaian konsumen terhadap fitur produk atau layanan, atau produk atau layanan itu sendiri, menyediakan tingkat kepuasan konsumen terhadap konsumsi mereka (Zeithaml, 2009:104).

Perusahaan perhotelan harus memberikan sesuatu yang maksimal dan terbaik untuk konsumennya. Kepuasan yang konsumen rasakan jika semakin tinggi, maka akan semakin tinggi pula tingkat konsumen untuk kembali membeli atau menginap di hotel tersebut (Jasinskas et al, 2016). Dikatakan bahwa agar berhasil mengoperasikan sebuah hotel yang memberikan konsumen sebuah pengalaman yang memuaskan, pengelola hotel perlu memahami apa yang pelanggan inginkan dan bagaimana mereka menilai kualitas layanan hotel (Festus et al , 2006).

Dalam hal untuk memuaskan pelanggan, berikut adalah 3 dimensi untuk dapat menentukan customer satisfaction menurut (Zeithaml, 2009:104)

\section{Satisfaction as fulfillment}

Adalah respon konsumen yang puas karena kebutuhan mereka terpenuhi. Dan juga dapat dilihat sebagai respon yang pasif (contentment) yang berarti bahwa konsumen tidak berfikir terlalu banyak dalam sebuah kualitas layanan yang mereka dapat. 


\section{Satisfaction as pleasure}

Adalah respon konsumen yang senang dan bahagia berhubungan dengan perusahaan (bertransaksi). Juga respon konsumen yang benar-benar puas atau lega karena adanya beberapa penghapusan hal negative oleh perusahaan secara cepat.

3. Satisfaction as ambivalence

Adalah mix felling dimana konsumen memiliki pengalaman positif dan negative mengenai suatu jasa yang dikonsumsinya.

\section{Customer Loyalty}

Customer Loyalty adalah konsumen yang berkomitmen kuat untuk membeli atau berlangganan lagi dengan produk atau jasa tertentu dimasa depan (Kotler \& Keller, 2009). Menurut pemahaman secara umum bahwa customer loyalty adalah pelanggan dengan komitmen yang kuat untuk berlangganan atau melakukan pembelian ulang untuk produk dan jasa yang disukai secara konsisten dimasa yang akan datang, meskipun adanya pengaruh situasi yang berpontensi untuk menimbulkan perilaku untuk berpindah. Menurut (Parasuraman, Zeithaml, \& Berry, 1996), tujuan akhir dari perusahaan adalah untuk menjalin relasi dengan konsumennya dan untuk membentuk loyalitas yang kuat. Dimensi dari loyalitas yang kuat adalah:

a. Say positive things about company, adalah mengatakan hal yang positif tentang barang atau jasa yang telah dikonsumsi kepada orang lain

b. Recommending the company to someone who seeks advice, adalah merekomendasikan barang atau jasa yang telah dikonsumsi kepada teman atau pihak lain bahkan mendorong teman untuk mengkonsumsi barang atau jasa tersebut.

c. Continue purchasing (doing more business with the company), adalah melakukan pembelian ulang di produk dan jasa yang pernah dikonsumsi sebelumnya

\section{Kerangka Konseptual}

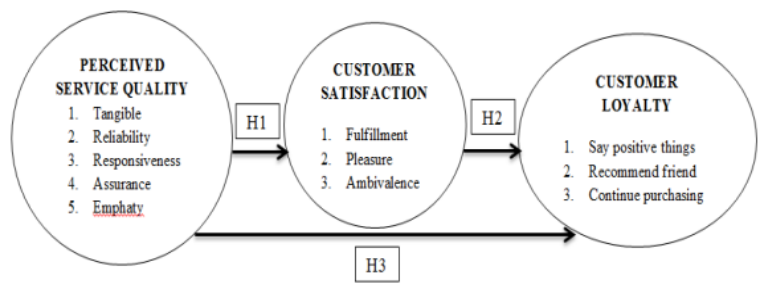

Gambar 1. Kerangka Konseptual

\section{Hipotesis}

H1: Diduga perceived service quality berpengaruh terhadap customer satisfaction di Hotel Kartika Graha Malang.

H2: Diduga customer satisfaction berpengaruh terhadap customer loyalty di Hotel Kartika Graha Malang.

H3: Diduga perceived service quality berpengaruh terhadap customer loyalty di Hotel Kartika Graha Malang.

\section{METODE PENELITIAN}

\section{Populasi}

Menurut Sugiyono (2013:215) populasi adalah sebagai wilayah generalisasi yang terdiri atas obyek atau subyek yang mempunyai kualitas dan karateristik tertentu yang ditetapkan oleh peneliti untuk dipelajari dan kemudian ditarik kesimpulannya. Didalam penelitian ini, penulis mengambil populasi yaitu semua orang yang pernah menginap di Hotel Kartika Graha Malang.

\section{Sample}

Menurut Sugiyono (2012:215) memberikan pengertian bahwa sampel adalah sebagian dari jumlah dan karakteristik yang di miliki oleh populasi. Adapun yang menjadi sampel dari penelitian ini adalah konsumen yang pernah menginap di Hotel Kartika Graha Malang minimal 1 hari/1 malam, tamu yang menginap dalam kurun waktu 6 bulan yaitu sejak November 2016 sampai April 2017 dan menginap bersama kelompok (keluarga atau bersama-sama dengan teman maupun kerabat) dalam rangka untuk liburan atau bersantai.

\section{Devinisi Operasional Variabel}

1. Variable Eksogen (X) yaitu perceived service quality. Pengukuran tersebut diukur dengan menggunakan 5 dimensi SERVQUAL yaitu,

$\mathrm{X} 1$. Tangible yaitu segala sesuatu yang menggambarkan wujud secara fisik yang mendukung operasional jasa.

X2. Reliability yaitu kemampuan perusahaan untuk melayani sesuai dengan apa yang dijanjikan secara akurat.

X3. Responsiveness yaitu kemampuan perusahaan untuk melayani konsumen dengan cepat dan tanggap. 
X4. Assurance yaitu perusahaan atau karyawan dapat membangun kepercayaan dan keyakinan terhadap konsumennya

X5. Emphaty yaitu sikap perhatian dan peduli penuh yang diberikan pada konsumen

2. Variable intervening $(\mathrm{Y})$ yaitu customer satisfaction. Pengukuran tersebut menggunakan dimensi sebagai berikut:

Y1. Satisfaction as fulfillment yaitu respon konsumen yang puas karena kebutuhan mereka terpenuhi

Y2. Satisfaction as pleasure yaitu respon konsumen yang senang dan bahagia berhubungan dengan perusahaan

Y3. Satisfaction as ambivalence yaitu mix feelling dimana konsumen memiliki pengalaman positif dan negative mengenai suatu jasa yang dikonsumsinya.

3. Variable endogen (Z) yaitu customer loyalty. Pengukuran variable loyalitas dapat diukur dengan 3 dimensi yaitu

Z1. Say positive things, yaitu mengatakan hal hal yang positif mengenai produk atau jasa yang telah dikonsumsi.

Z2. Recommending the company to someone who seeks advice, yaitu merekomendasikan barang atau jasa yang telah dikonsumsi kepada teman atau pihak lain.

Z3. Continue purchasing, yaitu melakukan pembelian ulang di produk dan jasa yang pernah dikonsumsi sebelumnya

\section{Teknik Analisa Data}

Setelah pengumpulan data, data-data tersebut harus diolah dan dianalisis terlebih dahulu sehingga dapat dijadikan dasar dalam pengambilan keputusan. Penelitian ini menggunakan pendekatan Structural Equation Modeling (SEM) dengan menggunakan path diagram. Analisa SEM yang digunakan adalah Partial Least Square (PLS) dengan proses perhitungan yang dibantu program aplikasi software SmartPLS.

\section{HASIL PENELITIAN DAN PEMBAHASAN}

\section{Profil Responden}

Berikut merupakan analisa deskriptif profil responden dari penelitian ini, dari total 100 responden dapat diketahui pada Tabel 1 .

Tabel 1 menunjukan bahwa responden dari Hotel Kartika Graha Malang yang menjadi sample penelitian adalah kebanyakan berusia diantara 41-50 tahun sebayak 35\% dan lainnya adalah 20-30 tahun sebanyak 25\%, diatas 50 tahun sebanyak 21\%. Hasil umur responden tersebut menunjukan bahwa mayoritas dari golongan berumur 41-50 tahun, hal tersebut disebabkan karena pada usia tersebut merupakan usia orang-orang yang sudah dewasa dalam keuangannya (mapan) dan ingin refreshing dari rutinitas keseharian mereka. Jika disangkut pautkan dengan responden menginap bersama dengan siapa, maka terlihat bahwa mayoritas responden menginap bersama keluarga mereka yaitu dengan membawa anak-anak sebanyak 55\% dan bersama keluarga dengan berpasangan (suami-istri) yaitu $24 \%$.

Durasi menginap responden dalam 6 bulan terakhir dalam kurun waktu sejak November 2016 hingga April 2017 terbanyak adalah sebanyak 1x dalam 6 bulan yaitu 85 orang (85\%). Selanjutnya untuk durasi responden dalam sekali menginap di Hotel Kartika Graha Malang kebanyakan adalah 2-3 malam sebesar 62\%, 1 malam 30\% dan yang terakhir adalah diatas 3 malam sebesar $8 \%$. Prosentase durasi dalam sekali menginap yang didapat dirasa sudah dapat memberikan informasi jelas tentang bagaimana pendapat konsumen/tamu akan kualitas layanan jasa yang diberikan oleh Hotel Kartika Graha Malang.

Tabel 1. Profil Responden

\begin{tabular}{llc}
\multicolumn{3}{c}{ Prosentase } \\
\hline Umur responden & 20-30 tahun & $(\%)$ \\
& $31-40$ tahun & $25 \%$ \\
& $41-50$ tahun & $19 \%$ \\
& diatas 50 tahun & $35 \%$ \\
& Keluarga suami istri & $21 \%$ \\
\hline Menginap bersama & Keluarga dengan anak- & $55 \%$ \\
& anak & \\
& Teman atau kerabat & $21 \%$ \\
\hline Durasi menginap 6 bulan 1 kali & $85 \%$ \\
terakhir & 2-3 kali & $14 \%$ \\
& diatas 3 kali & $1 \%$ \\
\hline Durasi dalam sekali & 1 malam & $30 \%$ \\
menginap & $2-3$ malam & $62 \%$ \\
& diatas 3 malam & $8 \%$ \\
\hline
\end{tabular}

\section{Analisa SEM-PLS}

\section{Analisa Partial Least Square}

Berdasarkan Gambar 2 terlihat bahwa customer satisfaction merupakan variabel intervening yang dimana memperkuat hubungan antara perceived service qualiy dengan customer loyalty yaitu sebesar $0.411(0.710 \times 0.579=0.411)$. Selain itu pada table bagan diatas juga terlihat bahwa perceived service quality tidak dapat berhubungan langsung dengan customer loyalty karena hanya menunjukan angka 
0.263 yaitu merupakan angka yang jauh lebih kecil dibanding dengan melalui variabel customer satisfaction.

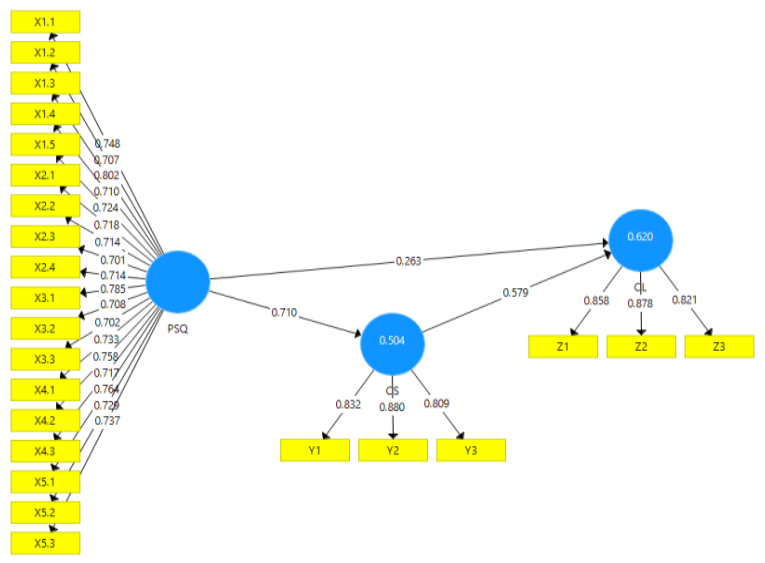

Gambar 2. Analisa Partial Least Square

Nilai coefficient determination $\left(\mathrm{R}^{2}\right)$ yang ada didalam bagan tersebut bisa dilihat dari angka yang ada didalam lingkaran customer satisfacation yang dipengaruhi perceived service quality yaitu sebesar 0.504 yang artinya variabel perceived service quality mempengaruhi customer sastisfaction sebesar 50.4\%. Selanjutnya variabel perceived service quality mempengaruhi customer loyalty sebesar 0.620 yang artinya perceived service quality mempengaruhi customer loyalty sebesar $62 \%$.

\section{T-Statistic dan Uji Hipotesis}

Tabel 2. T-Statistic

\begin{tabular}{|c|c|c|c|c|}
\hline & $\begin{array}{l}\text { Original } \\
\text { Sample } \\
\text { (O) }\end{array}$ & $\begin{array}{c}\text { Sample } \\
\text { Mean } \\
\text { (M) }\end{array}$ & $\begin{array}{l}\text { Standard } \\
\text { Deviation } \\
(\mathrm{STDEV})\end{array}$ & $\begin{array}{l}\text { T Statistics } \\
(|\mathrm{O} / \mathrm{STDEV}|)\end{array}$ \\
\hline $\begin{array}{l}\text { Customer } \\
\text { Satisfaction (Y) - } \\
\text { > Customer } \\
\text { Loyalty }(\mathrm{Z})\end{array}$ & 0.579 & 0.5825 & 0.0853 & 6.7851 \\
\hline $\begin{array}{l}\text { Perceived } \\
\text { Service Quality } \\
\text { (X) ->Customer } \\
\text { Loyalty (Z) }\end{array}$ & 0.2626 & 0.2599 & 0.1004 & 2.6155 \\
\hline $\begin{array}{l}\text { Perceived } \\
\text { Service Quality } \\
\text { (X)-> Customer } \\
\text { Satisfaction (Y) }\end{array}$ & 0.7098 & 0.7157 & 0.053 & 13.4013 \\
\hline
\end{tabular}

Pada table diatas diketahui bahwa semua variabel adalah memiliki hubungan yang signifikan karena berada diatas 1.96. sehingga dihaasilkan bahwa perceived service quality berpengaruh signifikan terhadap customer satisfaction, customer satisfaction berpengaruh signifikan terhadap customer loyalty dan perceived service quality berpengaruh signifikan terhadap customer loyalty.
Tabel 3. Uji Hipotesis

\begin{tabular}{llc}
\hline \multicolumn{1}{c}{ Keterangan } & T-statistic \\
\hline H1 & $\begin{array}{l}\text { Perceived service quality berpengaruh } \\
\text { signifikan terahadap customer satisfac- }\end{array}$ & 13.4013 \\
& \\
tion di Hotel Kartika Graha Malang & \\
\hline H2 & $\begin{array}{l}\text { Customer satisfaction berpengaruh } \\
\text { signifikan terhadap customer loyalty di }\end{array}$ & 6.7851 \\
& Hotel Kartika Graha Malang & \\
\hline H3 & $\begin{array}{l}\text { Perceived service quality berpengaruh } \\
\text { signifikan terhadap customer loyalty di }\end{array}$ & 2.6155 \\
& Hotel Kartika Graha Malang & \\
\hline
\end{tabular}

\section{Pembahasan}

Perceived Service Quality terhadap Customer Satisfaction

Di dalam penelitian ini membuktikan bahwa perceived service quality di Hotel Kartika Graha berpengaruh signifikan terhadap customer satisfaction di Hotel Kartika Graha dibuktikan dari hasil uji hipotesis dengan t-statistic sebesar 13.4013.

Hal ini juga sama dengan pendapat dari Saleem \& Raja (2014) dan (Tefera \& Govender, 2016) yang meneliti tentang persepsi tamu hotel di Ethiopian dan Pakistan, dikatakan bahwa semakin tinggi dan maksimal perceived service quality yang diberikan sebuah hotel kepada konsumen, maka akan meningkatkan customer satisfaction juga dalam inovasi kualitas layanan juga dikatakan dapat memampukan perusahaan meningkatkan kepuasan konsumen. Dalam hal ini kualitas layanan yang diberikan Hotel Kartika Graha ternyata diterima baik oleh konsumen dan ditanggapi baik oleh konsumen, dibuktikan dengan konsumen yang merasa puas dengan beberapa indikator kualitas layanan sehingga berpengaruh terhadap tingginya kepuasan konsumen menginap diHotel Kartika Graha.

\section{Customer Satisfaction terhadap Customer Loyalty}

Didalam penelitian ini membuktikan bahwa customer satisfaction di Hotel Kartika Graha berpengaruh signifikan terhadap customer loyalty di Hotel Kartika Graha dibuktikan dari hasil uji hipotesis dengan t-statistic sebesar 6.7851 .

Hal ini juga sama dengan pendapat (Saleem \& Raja, 2014) tentang persepsi tamu hotel di Ethiopian dikatakan bahwa ketika konsumen merasa puas maka mereka akan tetap loyal terhadap hotel tersebut dan ini berpengaruh terhadap rasa ingin kembali menginap dihotel tersebut. Dan dikatakan bahwa peningkatan kecil dalam hal kepuasan konsumen maka secara otomatis akan mendorong loyalitas konsumen juga dikatakan bahwa konsumen yang puas dan menjadi 
loyal akan memberikan banyak keuntungan untuk perusahaan (Chen, Bowen, \& Chen, 2001). Tingkat kepuasan konsumen berhubungan dengan loyalitas dibuktikan bahwa kepuasan konsumen akan kebutuhan mereka yang terpenuhi ketika menginap dan juga konsumen puas ketika menginap diHotel Kartika Graha menunjukan hubungan dengan keputusan konsumen untuk berbalik kembali menginap diHotel Kartika Graha bahkan berkata positif tentang Hotel Kartika Graha terhadap orang sekitar mereka.

\section{Perceived Service Quality terhadap Customer Loyalty}

Didalam penelitian ini membuktikan bahwa perceived service quality di Hotel Kartika Graha berpengaruh signifikan terhadap customer loyalty di Hotel Kartika Graha dibuktikan dari hasil uji hipotesis dengan t-statistic sebesar 2.6155.

Hal ini juga sama dengan pendapat (Saleem \& Raja, 2014) dikatakan bahwa ketika sebuah service quality ditingkatkan maka itu akan membuat konsumen menempel dan loyal pada sebuah hotel di Ethiopian hotel. Juga diperkuat dengan Amissah (2013) yang meneliti tentang kepuasan turis dengan service pada hotel di Cape Coast dan Elmina, Ghana dikatakan bahwa adanya hubungan yang kuat antara service quality yang diterima tamu hotel dengan revisit intention yang merupakan indikator customer loyalty. Berarti dalam penelitian ini dihasilkan jika service quality pada Hotel Kartika Graha semakin baik maka customer loyalty juga akan semakin meningkat. Contohnya adalah seperti Pemberian keandalan karyawan memberikan pelayanan, ketepatan daya tangkap pegawai dalam menanggapi keluhan konsumen, pemberian jaminan pelayanan, dan pemberian perhatian terhadap konsumen akan mmbuat konsumen konsumen memberikan word of mouth yang positif dan menginap kembali di Hotel Kartika Graha.

\section{KESIMPULAN DAN SARAN}

\section{Kesimpulan}

Didalam penelitian ini menghasilkan variablevaribel yang dipakai dalam penelitian adalah berpengaruh satu sama lain. perceived service quality berpengaruh signifikan terhadap customer satisfaction, customer satisfaction berpengaruh signifikan terhadap customer loyalty dan perceived service quality berpengaruh signifikan terhadap customer loyalty.
Penelitian ini pula menunjukan hasil bahwa variabel customer satisfaction terbukti menjadi variabel intervening dan memiliki pengaruh yang besar antara perceived service quality dengan customer loyalty, daripada pengaruh langsung dari perceived service quality ke customer loyalty.

\section{Saran}

Hotel Kartika Graha dapat memaksimalkan kepuasan konsumen dengan me-maintenance tiap kamar bukan hanya beberapa kamar saja dan juga sudut-sudut hotel lebih rutin Caranya bisa dengan memberikan hiasan-hiasan atau gambar-gambar yang menarik untuk mempercantik estetika hotel, juga dalam peralatan untuk kamar maupun kamar mandi yang sudah using/kuno diupgrade dengan peralatan yang modern, dan juga karpet yang ada disarankan untuk dibersihkan secara rutin atau bisa juga diganti agar tidak terlihat kotor dan usang. Juga dapat memperbarui bahkan menambah fasilitas-fasilitas didalam hotel misalnya saja dengan menambah beberapa komputer dilengkapi dengan internet agar konsumen ketika menunggu kendaraan atau menunggu checkin/check-out dengan santai dan juga bisa dipakai untuk pada saat konsumen urgent membutuhkan komputer.

Selain itu Hotel Kartika Graha dapat memberikan hiburan pada konsumen, seperti tiap-tiap weekend maupun hari liburan yang memiliki occupancy room tinggi sebaiknya dimanfaatkan pihak hotel untuk meng-entertain konsumen dengan memberikan pertunjukan gratis yang dapat ditonton konsumen, tarian daerah malang atau bahkan pameran-pameran untuk memberikan pengalaman yang berkesan kepada konsumen. Dengan memaksimalkan perceived service quality diharapkan supaya Hotel Kartika Graha bisa lebih baik lagi dimasa yang akan datang dan konsumen Hotel Kartika Graha dapat merasa puas dan loyal terhadap Hotel Kartika Graha.

\section{DAFTAR PUSTAKA}

Amissah, E. F. (2013). Tourist Satisfaction with Hotel Services in Cape Coast and, 2, 26-33. https://doi.org/10.5923/s.tourism.201304.03

Chen, J. T. B. S., Bowen, J. T., \& Chen, S. (2001). The relationship between customer loyalty and customer satisfaction The relationship between customer loyalty and customer satisfaction.

Festus Olorunniwo, Maxwell K.Hsu, \& Godwin J. Udo. (2006). Service quality, customer satisfaction, and behavioral intentions in the service factory. Journal of Services Marketing, 20(1), 5972. http://doi.org/10.1108/08876040610646581 
Jasinskas, E., Streimikiene, D., Svagzdiene, B., \& Simanavicius, A. (2016). Impact of hotel service quality on the loyalty of customers. Economic Research-Ekonomska Istraživanja, 29(1), 1-14. https://doi.org/10.1080/1331677X.2016. 1177465

Kotler, P., \& Keller, K. L. (2009). Marketing Management (13th Editi). Pearson Education International.

Parasuraman, A., Zeithaml, V., \& Berry, L. (1985). Conceptual model of service quality and its implications for future research. Journal of Marketing, 49(fall 1985), 41-50. https://doi.org/ 10.1016/S0148-2963(99)00084-3

Parasuraman, A., Zeithaml, V., \& Berry, L. (1996). The Behavioral Consequences of, 60(April), 31-46.

Parasuraman et al. (1988). SERVQUAL: A MultipleItem Scale for Measuring Consumer Perceptions of Service Quality, 64(1).

Saleem, H., \& Raja, N. S. (2014). The impact of service quality on customer satisfaction, customer loyalty and brand image: Evidence from hotel industry of Pakistan. Middle - East Journal of Scientific Research, 19(5), 706-711. https://doi.org/10.5829/idosi.mejsr.2014.19.5.21 018.
Stefano, N. M., Casarotto Filho, N., Barichello, R., \& Sohn, A. P. (2015). A fuzzy SERVQUAL based method for evaluated of service quality in the hotel industry. Procedia CIRP, 30 (December), 433-438. https://doi.org/10.1016/j.procir. 2015.02.140

Sugiyono. (2012). Metode Penelitian Kuantitatif Kualitatif dan R\&D. Bandung: Alfabeta.

Sugiyono. (2013). Statistika Untuk Penelitian. Bandung: Alfabeta.

Tefera, O., \& Govender, K. (2016). Hotel Ratings , Service Quality, Customer Satisfaction and Loyalty: The Perception of Guests at Ethiopian Hotels, 5(3), 1-23.

Vazquez, R., Bosque, I.A.R. Del, Diaz, A.M., \& Ruiz, A. V. (2000). Service quality in supermarket retailing: Identifying critical service experiences. Journal of Retailing and Consumer Services, 8(1), 1-14. https://doi.org/10.1016/ S0969-6989(99)00018-1

Zeithaml, V.A., A. Parasuraman, dan L.L.B. (1990). Delivering Quality Services, Free Press, New York.

Zeithaml, Valarie A., M.J.B. \& D.D.G. (2009). Service Marketing: Integrating Customer Focus Across The Firm 5th ed. New York: McGrawHill. 